\title{
Case report: uniportal video-assisted thoracoscopic resection of a solitary fibrous tumor preoperatively predicted visceral pleura origin using dynamic chest radiography
}

Masaya Tamura*, Isao Matsumoto, Daisuke Saito, Shuhei Yoshida, Munehisa Takata and Hirofumi Takemura

\begin{abstract}
Background: Dynamic chest radiography (DCR) is a flat-panel detector (FPD)-based functional X-ray imaging, which is performed as an additional examination in chest radiography. DCR provides objective and quantifiable information, such as diaphragm movement, pulmonary ventilation and circulation, and is reasonable for detecting tumor invasion or adhesion.

Case presentation: We present a case of Solitary Fibrous Tumor of Pleura (SFTP), preoperatively predicted visceral pleura origin using Dynamic chest radiography (DCR) and surgically resected through single-access (uniportal) videoassisted thoracoscopic surgery (UVATS).

Conclusions: UVATS may be a suitable surgical option for pedunculated SFTPS. Dynamic chest radiography provides information, such as tumor invasion or adhesion and helpful for predicting origin of the tumor.

Keywords: Dynamic chest radiography, Solitary fibrous tumor of the pleura, Uniportal video- assisted thoracoscopic surgery
\end{abstract}

\section{Background}

Dynamic chest radiography (DCR) is a flat-panel detector (FPD)-based functional X-ray imaging, which is performed as an additional examination in chest radiography. DCR contain a wealth of functional information, such as diaphragm movement, cardiac motion, pulmonary ventilation and circulation. The first clinical report of this technique was published by the author's group [1]. This modality has a potential to make an accurate diagnosis of tumor invasion or adhesion to the parietal pleura, and that visual (qualitative) assessment for cancer

\footnotetext{
* Correspondence: masatamu2007@yahoo.co.jp

Department of Thoracic, Cardiovascular and General Surgery, Kanazawa University, Takara-machi 13-1, Kanazawa 920-8640, Japan
}

invasion. We present a case of Solitary fibrous tumor of the pleura (SFTP), preoperatively predicted visceral pleura origin using Dynamic chest radiography (DCR) and surgically resected through single-access (uniportal) video-assisted thoracoscopic surgery (UVATS).

\section{Case presentation}

A 60-year-old man was admitted to our hospital for further examinations of an abnormal shadow found on a chest CT. A CT scan demonstrated a homogenous, sharply-circumscribed mass in the posterior mediastinum (Fig. 1). Additional file 1A (Video) showed preoperative DCR findings. Two points for measurements on the inspiratory frame of the dynamic-ventilation. One

C The Author(s). 2020 Open Access This article is licensed under a Creative Commons Attribution 4.0 International License, which permits use, sharing, adaptation, distribution and reproduction in any medium or format, as long as you give appropriate credit to the original author(s) and the source, provide a link to the Creative Commons licence, and indicate if changes were made. The images or other third party material in this article are included in the article's Creative Commons licence, unless indicated otherwise in a credit line to the material. If material is not included in the article's Creative Commons licence and your intended use is not permitted by statutory regulation or exceeds the permitted use, you will need to obtain permission directly from the copyright holder. To view a copy of this licence, visit http://creativecommons.org/licenses/by/4.0/ The Creative Commons Public Domain Dedication waiver (http://creativecommons.org/publicdomain/zero/1.0/) applies to the data made available in this article, unless otherwise stated in a credit line to the data. 
A

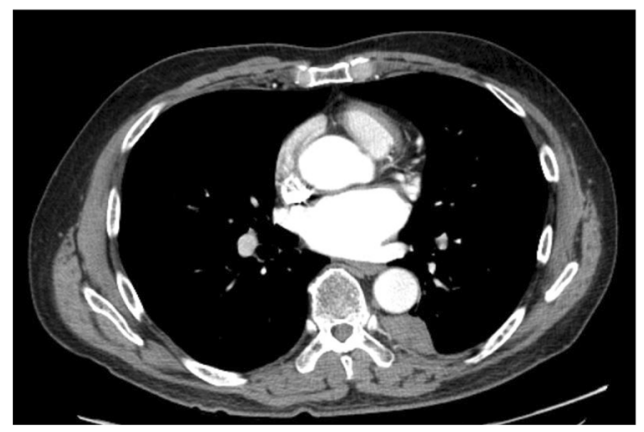

B

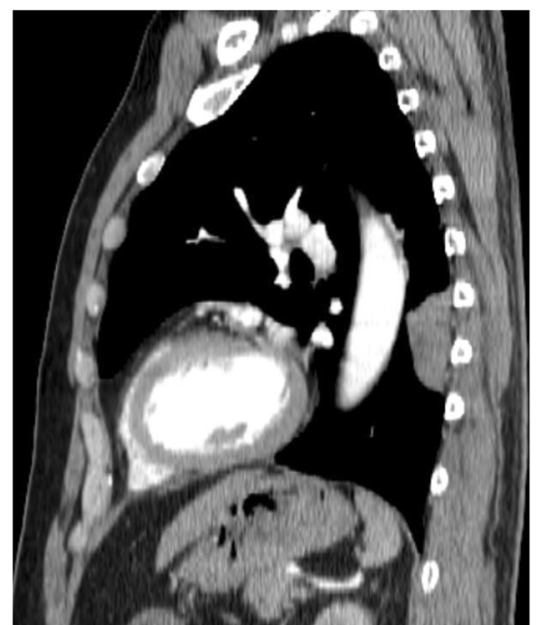

Fig. 1 Preoperative chest computed tomography (CT) scan demonstrated a homogenous, sharply-circumscribed mass in the posterior mediastinum. a Enhancement showed a mass that was not enhanced. b Sagittal view

point was placed in the center of the targeted lesion (red point). The other point was the vertebra adjacent to the tumor (blue point). The software automatically tracked these two measuring points, and coordinates were recorded. The distance of the two points (Additional file 1B), movement in two directions (Additional file 1C) were not coincidence, which means no invasion or adhesion of the tumor to the chest wall.

The patient had a CT guided biopsy, and histopathology examination revealed benign solitary fibrous
A

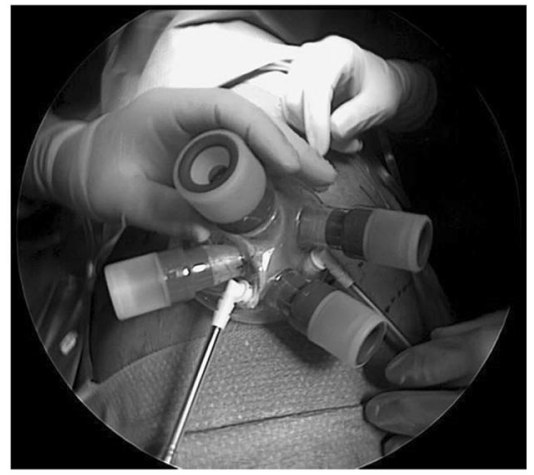

B

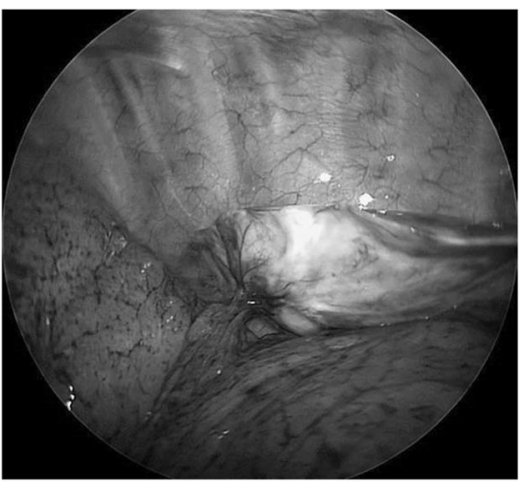

$\mathrm{C}$

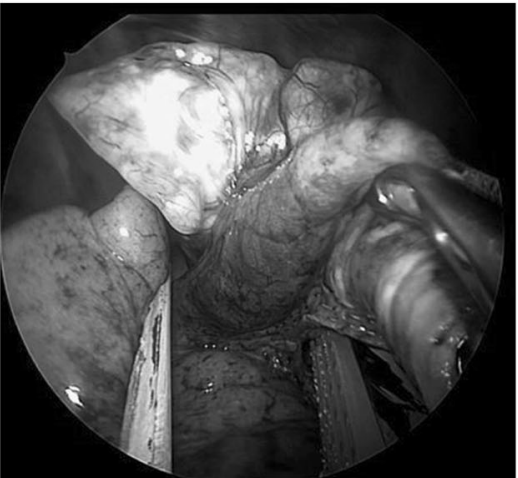

Fig. 2 Intraoperative findings. a A $3.0 \mathrm{~cm}$ skin incision was made, and the Lap-protector (alnote LapSingleTM, Applied Alfresa Pharma Coroperation, Japan) was then placed through the incision. b A pedunculated tumor protruded into the thoracic cavity from the visceral pleura, and was attached to the left lower lobe. c The tumor stalk was resected using an articulating endostapler (Covidien, Norwalk, CT, USA) 
tumor. However, surgery was required for curative resection. The patient was administered under general anesthesia using one-lung ventilation and was placed in a lateral position. The $3 \mathrm{~cm}$ incision located of the midaxillary line at the level of the sixth intercostal space, and the Lap-protector (alnote LapSingleTM, Applied Alfresa Pharma Coroperation, Japan) was then placed through the incision (Fig. 2a). We applied $\mathrm{CO} 2$ gas insufflation to push the lung down. We start the $\mathrm{CO} 2$ insufflation at $31 / \mathrm{min}$, with a pressure of $5 \mathrm{mmHg}$, while the $\mathrm{CO} 2$ still allows for a generous space which allows the surgery to be undertaken. A pedunculated tumor that protruded into the thoracic cavity from the visceral pleura was observed. The tumor was attached by its stalk to the left lower lobe, and moved freely (Fig. 2b). We believed that a single-port surgery was feasible for this type of lesion. The tumor stalk was resected using an articulating endostapler (Covidien) (Fig. 2c).

Microcopically, the tumor was characterized by spindle cells that were organized in short fascicles against a collagenous background. Areas of high cellularity and mitotic activity were absent (Fig. 3). Immunohistochemical staining was strongly positive for CD34, STAT6 in the cytoplasm of the tumor cells. The final pathology was determined a benign SFTP. The patient was followed-up for 6 months, and no evidence of recurrence was observed.

\section{Discussion}

Dynamic chest radiography provides objective and quantifiable information, such as diaphragm movement, pulmonary ventilation and circulation, and is reasonable for detecting tumor invasion or adhesion. Sakuma et al. [2] reported that dynamic-ventilation CT can be utilized as a novel imaging approach for the preoperative assessment of pleural invasion and adhesion. The total radiation exposure for the dynamic ventilation CT ranged from 4.2 to $6.1 \mathrm{mSv}$. The total patient dose of DCR is $0.23 \mathrm{mSv}$, about double that of conventional chest radiography [1]. The DCR is acceptable because of the increased yield of information, low radiation exposure, simple and rapid means of functional imaging. Since chest X-ray is routinely performed as a standard preoperative assessment of patients with lung cancer, we currently believe that the addition of DCR to conventional chest X-ray is reasonable for obtaining diagnosis of tumor invasion or adhesion of the parietal pleura. A prospective study enrolling a larger number of patients is now ongoing.

SFTP is a relatively rare pleural tumor that generally arises from the visceral pleura as an asymptomatic pleural-based mass [3]. Although most SFTPs are considered as histologically benign, local recurrences and enlargements without any signs of invasion or metastasis have been reported [4]. SFTP usually arises from the visceral pleura, although an origin from the parietal or the diaphragmatic pleura has been reported in about $20 \%$ of the cases [5].

Recently, VATS has become a more commonly used technique for thoracic tumor surgeries [6]. In particular, UVATS has been useful for specific diseases, such as pneumothorax [7]. Pulmonary anatomical resections through UVATS started in 2010 [8], and then have experienced a huge worldwide spread. Nowadays, there are reports of uniportal tracheal resection and reconstruction, bronchoplastic procedures, lobectomies with en bloc chest wall excision, and vascular reconstruction with optimal outcomes [9]. Because only one intercostal space is involved, the possible advantages of UVATS include less postoperative pain, fewer postoperative
A

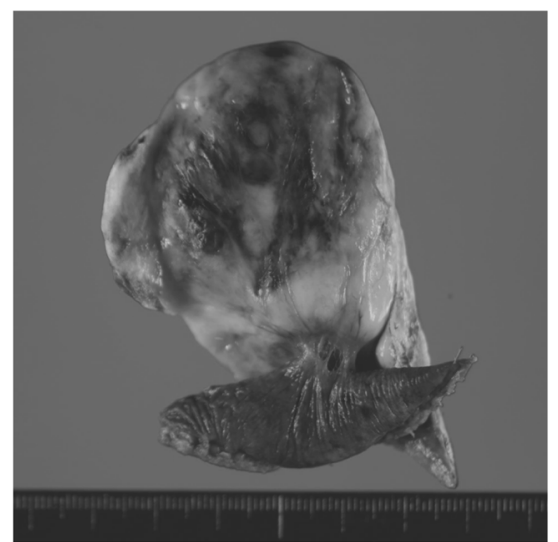

B

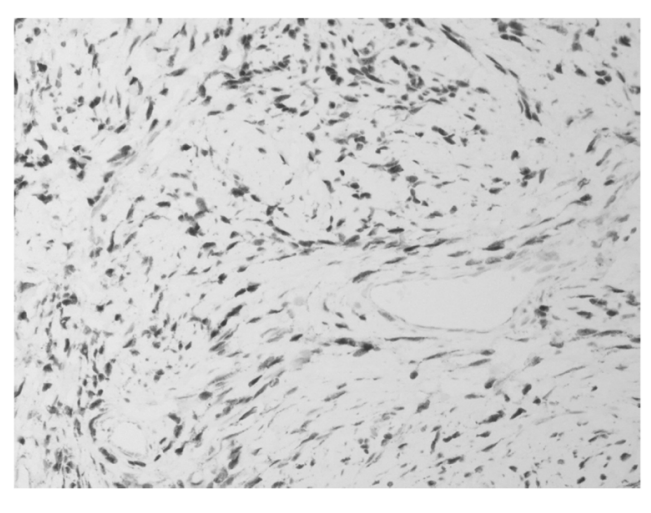

Fig. 3 a Cut surface of the resected specimen demonstrated a smooth margin with solid consistency and a heterogeneous appearance (7.5 $x$ $4.7 \times 1.5 \mathrm{~cm}$ ). $\mathbf{b}$ Histological specimen demonstrated that the tumor consisted of hypocellular and moderately cellular areas of bland spindle cells in abundant collagen fibers. (Hematoxylin and eosin, $\times 200$ ) 
drainage days, shorter hospital stays, and cosmetic advantages compared with those of conventional threeport VATS. Some authors have reported less postoperative pain and less paresthesia in patients who underwent minor procedures through a single-port approach compared with the classical three-port approach $[10,11]$.

There are obvious technical problems with UVATS. UVATS is not a naturally ergonomic procedure, because the traditional thoracoscopic principles of triangulation are lost. In addition, positioning of multiple devices poses a problem because they are passed through a single small incision in the chest. We applied $\mathrm{CO} 2$ gas insufflation to push the lung and diaphragm down using uniportal thoracoscopic surgery port. The $\mathrm{CO} 2$ insufflation is known to make the uniportal VATS procedure easier by flattening the lung and diaphragm.

\section{Conclusion}

We recommend the minimally invasive UVATS for resecting a thoracic pedunculated SFTP. DCR may play a great role for predicting the origin of the tumor preoperatively.

\section{Supplementary information}

Supplementary information accompanies this paper at https://doi.org/10. 1186/s13019-020-01212-0

Additional file 1. Dynamic chest radiography findings. A: Video showed preoperative DCR findings. B: Red point; the center of the targeted lesion. Blue point; the vertebra adjacent to the tumor. The Figure shows the distance of the two points. C: Movement in two directions were not coincidence, which means no invasion or adhesion of the tumor to the chest wall.

\section{Abbreviations}

DCR: Dynamic chest radiographys; SFTP: Solitary fibrous tumor of the pleura; UVATS: Uniportal video-assisted thoracoscopic surgery

\section{Acknowledgements}

Not applicable.

\section{Authors' contributions}

DS, SY and MUT analyzed and interpreted the patient data. MaT performed the literature review, and was a major contributor in writing the manuscript. IM and HT performed the final editing of the manuscript. All authors read and approved the final manuscript.

\section{Funding}

Not applicable.

Availability of data and materials

Not applicable.

\section{Ethics approval and consent to participate}

Ethical approval was obtained from the institutional review board at the University School of Medicine.

\section{Consent for publication}

Written informed consent was obtained from the patient for publication of this case report and any accompanying images. A copy of the written consent is available for review by the Editor- in- chief of this journal.

\section{Competing interests}

The authors declare that they have no competing interests.

Received: 30 January 2020 Accepted: 29 June 2020

Published online: 08 July 2020

\section{References}

1. Tanaka R, Sanada S, Okazaki N, Kobayashi T, Fujimura M, Yasui M, et al. Evaluation of pulmonary function using breathing chest radiography with a dynamic flat-panel detector (FPD): primary results in pulmonary disease. Investig Radiol. 2006:41:735-45.

2. Sakuma K, Yamashiro T, Moriya H, Murayama S, Ito H. Parietal pleural invasion/adhesion of subpleural lung cancer: quantitative 4-dimensional CT analysis using dynamic-ventilatory scanning. Eur J Radiol. 2017;87:36-44.

3. Harrison-Phipps KM, Nichols FC, Schleck CD, Deschamps C, Cassivi SD, Schipper $\mathrm{PH}$, et al. Solitary fibrous tumors of the pleura: results of surgical treatment and long-term prognosis. J Thorac Cardiovasc Surg. 2009;138:19-25.

4. de Perrot M, Fischer S, Brundler MA, Sekine Y, Keshavjee S. Solitary fibrous tumors of the pleura. Ann Thorac Surg. 2002;74:285-93.

5. Usami N, Iwano S, Yokoi K. Solitary fibrous tumor of the pleura: evaluation of the origin with 3D CT angiography. J Thorac Oncol. 2007;12(2):1124-5.

6. Shapiro M, Weiser TS, Wisnivesky JP, Chin C, Arustamyan M, Swanson SJ. Thoracoscopic sementectomy compares favorably with thoracoscopic lobectomy for patients with small stage I lung cancer. J Thorac Cardiovasc Surg. 2009;137:1388-93.

7. Gigirey Castro O, Berlanga Gonzalez L, Sanchez Gomez E. Single port thoracoscopic surgery using the SILS tool as a novel method in the surgical treatment of pneumothorax. Arch Bronconeumol. 2010;46:439-41.

8. Gonzalez D, Paradela M, Garcia J, Dela Torre M. Single-port video-assisted thoracoscopic lobectomy. Interact Cardiovasc Thorac Surg. 2011;12:514-5.

9. Guido GW, Bolanos CA, Gonzalez RD. Single-port video-assisted thoracic surgery (VATS)-advanced procedure \& update. J Thorac Dis. 2018;10:1652-61.

10. Salati M, Brunelli A, Xiume F, Refai M, Sciarra V, Soccetti A, et al. Uniportal video-assisted thoracic surgery for spontaneous pneumothorax: clinical and economic analysis in comparison to the traditional approach. Interact Cardiovasc Thorac Surg. 2008;7:63-6.

11. Jutley RS, Khalil MW, Rocco G. Uniportal vs standard three-port VATS technique for spontaneous pneumothorax: comparison of post-operative pain and residual paraesthesia. Eur J Cardiothorac Surg. 2005;28:43-6.

\section{Publisher's Note}

Springer Nature remains neutral with regard to jurisdictional claims in published maps and institutional affiliations.
Ready to submit your research? Choose BMC and benefit from:
- fast, convenient online submission
- thorough peer review by experienced researchers in your field
- rapid publication on acceptance
- support for research data, including large and complex data types
- gold Open Access which fosters wider collaboration and increased citations
- maximum visibility for your research: over $100 \mathrm{M}$ website views per year
At BMC, research is always in progress.
Learn more biomedcentral.com/submissions 